\title{
Power Quality Improvement using Voltage Source Converter (VSC) based Unified Power Quality Conditioner (UPQC)
}

\author{
Saima Ashraf \\ (M. Tech Scholar), \\ EEE Department, \\ Manav Rachna International \\ University, Faridabad, Haryana, \\ India.
}

\author{
Anita Khosla, $\mathrm{PhD}$ \\ (Associate Professor), \\ EEE Department, \\ Manav Rachna International \\ University, Faridabad, Haryana, \\ India.
}

\author{
Abdul Hamid Bhat, PhD \\ (Associate Professor), \\ EE Department, \\ National Institute of Technology, \\ Srinagar, Jammu and Kashmir, \\ India.
}

\begin{abstract}
In recent years, there is tremendous growth in the use of power electronic devices in every sphere but in nonlinear loads, it has problem of drawing the two important limitations; draws the non-sinusoidal current and reactive power from source which in turn effects the power quality. This paper presents the performance evaluation of unified power quality conditioner (UPQC) for current and voltage harmonic elimination and improved power factor. The combined operation of shunt active power filter and series active power filter ensures THD of source current and load voltage within the permissible limits set by various regulatory agencies and near unity supply power factor. The effectiveness of the UPQC has been verified by the extensive simulation results carried out in MATLAB/Simulink and SimPowerSystem software. The results have been obtained with PI Controller and Fuzzy Logic Controller and then compared.
\end{abstract}

\section{Keywords}

Power Quality, UPQC, PI, Fuzzy Logic, VSC, Total Harmonic Distortion (THD).

\section{INTRODUCTION}

In a modern power system due to the wide use of nonlinear loads such as adjustable speed drives, furnaces, and electric arc welders, it has become necessary to establish criteria for limiting power quality problems. These problems cause reduction in system efficiency, poor power factor, maloperation of electronics equipment and reduction in equipment mean life time. There has been an increased use of power electronics equipment due to low cost and new technologies causing an increased interest for research and development in the area [1]. Active power filters (APFs) that have been explored in shunt, series and combination of shunt and series configurations to compensate for current and voltage based distortions will play an important role for better quality solutions [1],[2].

Voltage and current harmonics have become a serious problem in transmission and distribution systems in recent years. As a result of this non-sinusoidal voltage drop occurs across the various network elements connected to the system resulting in distorted waveform propagation throughout the system [6].To solve the current and voltage harmonics related problems, the Unified Power Quality Conditioner (UPQC) is one such modern device used for mitigating the effect of voltage and current related problems [4].Unified Power Quality Conditioner (UPQC) is a combination of both series and shunt active power filters which compensate the distortions of both source voltages and load currents [7]. It is used for harmonic elimination and simultaneous compensation of voltage and current, and hence improves the power quality offered by the harmonic sensitive loads [5].

\section{THE UNIFIED POWER QUALITY CONDITIONER}

The Unified Power Quality Conditioner (UPQC) consists of two Voltage Source Converters (VSC), one is shunt APF connected to the power system, and another is series APF which is connected in series with the load. The two converters are connected back to back by a common DC bus and deals with both load current and supply voltage imperfections. The block diagram is shown in Figure 1. Different topologies/configurations of UPQC have been proposed in the literature [8],[9].

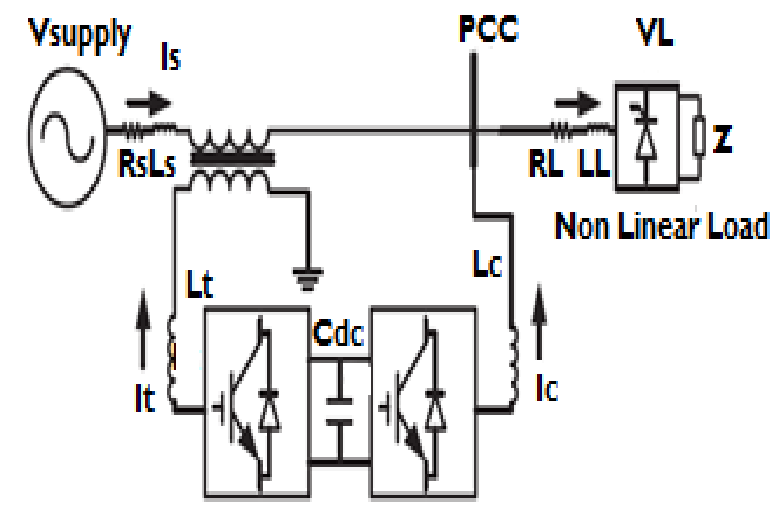

Series APF Shunt APF

Figure 1. Block diagram of UPQC configuration.

In other words, UPQC has the capability of improving power quality at the point of installation on the power distribution systems or industrial power systems. The author describes the comprehensive review [10] of Active filter (AF) configure durations, control strategies, selection of components, other related economic and technical considerations, and their selection for specific application. Efforts have been made to improve the power quality using active power filters, passive filters, hybrid filters [11]. Ghosh and Ledwitch proposed unified power quality conditioner for voltage and current compensation [12]. Many have been proposed the control schemes based on PI and fuzzy controller based UPQC [14],[15]. 
In this work, UPQC has been modeled for both active and reactive power compensation using PI and fuzzy logic control strategies. Extensive simulation results using Matlab/Simulink SimPowerSystem software for R-L load connected through an uncontrolled bridge rectifier is presented for performance evaluation.

\section{SYSTEM MODELING AND DESCRIPTION}

In this section, the UPQC modeling has been presented considering the equivalent circuit as shown in Figure 2, here $V_{S}$ is the supply voltage, $V_{c}$ and $i_{c}$ are the series compensation voltage, shunt compensation current and $V_{L}, i_{L}$ are the load voltage and load current respectively.

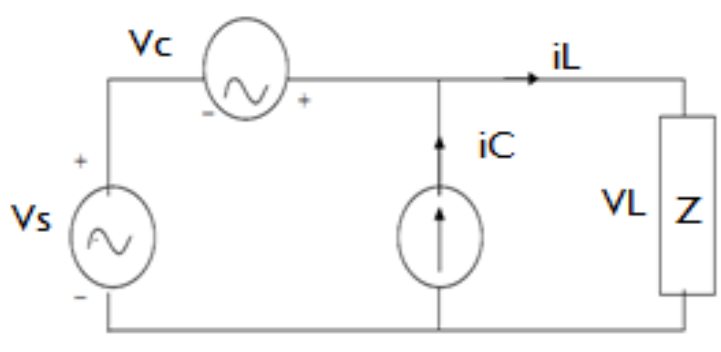

Figure 2. Equivalent circuit diagram of UPQC

The source voltage may contain positive, negative and zero sequence components as well as harmonic components. The per phase voltage of the system can be expressed as:

$V_{s a}=V_{1 p a}+V_{1 n a}+V_{10 a}+\sum_{k=2}^{\infty} V_{k a} \sin \left(\mathrm{k} \omega \mathrm{t}+\theta_{k a}\right) \ldots \ldots .(1)$

Here $V_{s a}$ is the Per Phase voltage. $V_{1 p a}$, is the Fundamental Frequency Positive Sequence Component. $V_{1 \text { na }}$ and $V_{10 n a}$ are Negative and Zero Sequence Components respectively. Now for the load voltage to be perfectly sinusoidal and balanced, the series filter should produce a voltage equal to

$V_{a h}=V_{1 n a}+V_{10 a}+\sum_{k=2}^{\infty} V_{k a} \sin \left(\mathrm{k} \omega+\theta_{k a}\right)$.

The per phase load current of shunt active filter is expressed as:

$i_{a l}=i_{a 1 p} \cos \left(\omega \mathrm{t}-\theta_{1}\right)+i_{a 1 n}+\sum_{k=2}^{\infty} i_{a l k}$

$i_{a l}=i_{a 1 p} \cos (\omega \mathrm{t}) \cos \left(\theta_{1}\right)+i_{a 1 p} \sin (\omega \mathrm{t}) \sin \left(\theta_{1}\right)+i_{a i n}+\sum_{k=2}^{\infty} i_{a l k} \ldots$

For compensation of harmonic current and meeting the reactive power demand the shunt active filter should produce a current of

$i_{a h}=i_{a 1 p} \sin (\omega \mathrm{t}) \sin \left(\theta_{1}\right)+i_{a 1 n}+\sum_{k=2}^{\infty} i_{a l k}$

Therefore, source current is

$i_{a s}=i_{a l}-i_{a h}=i_{a 1 p} \cos (\omega \mathrm{t}) \cos \left(\theta_{1}\right)$

Thus the source current will be free from harmonics and will be in phase with source voltage.

\section{CONTROL STRATEGIES}

The basics of the hysteresis current control is based on an error signal between an injected current ( $\left.I_{i n j}\right)$, and a reference current of APF ( $I_{r e f}$ ), which produces proper control signals. Hysteresis current control algorithm is used for control of both shunt and series active power filter. It comprises of the following components:

\subsection{Unit Vector Template Generation}

The input source voltage at point of common coupling contains fundamental and distorted component. To get unit vector templates of voltage, the input voltage is sensed and multiplied by gain equal to $1 N_{m}$, where $V_{m}$ is peak amplitude of fundamental input voltage. These unit vector templates are then passed through a multiplication block for synchronization of signals. The unit vector templates for different phases are obtained as follows:

$V_{s a}=\sin \omega \mathrm{t}$

$V_{s b}=\sin \left(\omega \mathrm{t}-120^{\circ}\right)$

$V_{S C}=\sin \left(\omega \mathrm{t}+120^{\circ}\right)$

\subsection{Reference Source Current Estimation}

The peak value of the reference current $\mathrm{I}_{\mathrm{sp}}$ can be estimated by controlling the DC side capacitor voltage. The ideal compensation requires the mains current to be sinusoidal and in phase with the source voltage irrespective of load current nature. The desired source current after compensation can be given as,

$\mathrm{i}_{\mathrm{sa}}^{*}=\mathrm{I}_{\mathrm{sp}} \sin \omega \mathrm{t}$

$\mathrm{i}_{\mathrm{sb}}^{*}=\mathrm{I}_{\mathrm{sp}} \sin \left(\omega \mathrm{t}-120^{\circ}\right)$

$\mathrm{i}_{\mathrm{sc}}^{*}=\mathrm{I}_{\mathrm{sp}} \sin \left(\omega \mathrm{t}+120^{\circ}\right)$

Where $\left(I_{\mathrm{sp}}=\mathrm{I}_{1} \cos \emptyset_{1}+\mathrm{I}_{\mathrm{sL}}\right)$ is the amplitude of the desired source current. Thus the peak value of the reference current has been estimated by regulating the dc side capacitor voltage of PWM converter. This capacitor voltage is compared by a reference value and thus the error is processed in a PI controller.

\subsection{Control Algorithm}

The implementation of control algorithm is where the actual source currents $\left(\mathrm{i}_{\mathrm{sa}}, \mathrm{i}_{\mathrm{sb}}\right.$, andi $\left.\mathrm{sc}_{\mathrm{sc}}\right)$ are compared in hysteresis current controller to generate the control pulses for switches in such a way that the actual source current follows the reference currents closely within the narrow hysteresis band. This makes source currents nearly sinusoidal and in phase with source voltages, thus giving unity power factor [13]

\subsection{Hysteresis Current Control Scheme}

The hysteresis current controller band decides the switching pattern of APF. There are bands above and under the reference current. When the error reaches to the upper limit, the current is forced to decrease. When the error reaches to the lower limit, the current is forced to increase. The increased current harmonics due to large hysteresis band are removed effectively by a high pass filter, thus resulting in reduced source current THD at higher efficiency.

\subsection{The Proposed Fuzzy Logic Based \\ Controller}

Artificial intelligence is one of the major fields developed since past four decades, and is very popular due to its ability to handle complex problem at difficult situations. These tools of artificial intelligence (fuzzy logic, artificial neural network, genetic algorithms etc.) are used for improving the power quality effectively and produce good performances. In this paper the conventional PI voltage controller is replaced by fuzzy logic controller. This scheme is tested for compensating the line current, compensate the harmonics pollution [3] and regulate the DC bus voltage. The fuzzy controller is characterized as follows: 
i. $\quad 7$ fuzzy sets for each input and output.

ii. Triangular membership functions for simplicity.

iii. Fuzzification

iv. Implication using Mamdani's 'min' operator.

v. Defuzzification

A sample rule from table I is Rule 10: IF the error is (NM) AND error rate is (NS), THEN the output is (NB).

Table 1: Rule Base Representation

\begin{tabular}{|l|l|l|l|l|l|l|l|}
\hline $\mathbf{A E}$ & NB & NM & NS & $\mathbf{Z}$ & PS & PM & PB \\
\hline NB & NB & NB & NB & NB & NM & NS & Z \\
\hline NM & NB & NB & NB & NM & NS & Z & PS \\
\hline NS & NB & NB & NM & NS & $Z$ & PS & PM \\
\hline $\mathbf{Z}$ & NB & NM & NS & $Z$ & PS & PM & PB \\
\hline PS & NM & NS & $Z$ & PS & PM & PB & PB \\
\hline PM & NS & $Z$ & PS & PM & PB & PB & PB \\
\hline PB & $Z$ & PS & PM & PB & PB & PB & PB \\
\hline
\end{tabular}

\section{SIMULATION RESULTS OF UPQC}

The system is first evaluated with PI Controller and then PI Controller is replaced by Fuzzy Logic Controller in VSC based Unified Power Quality Conditioner (UPQC).

\subsection{Simulation Results Using PI Controlled VSC Based UPQC}

In Figure 3, the load voltage is same as that of source voltage, till the series filter is switched on, as the series filter is switched on at 0.1 second, the load voltage becomes purely sinusoidal.

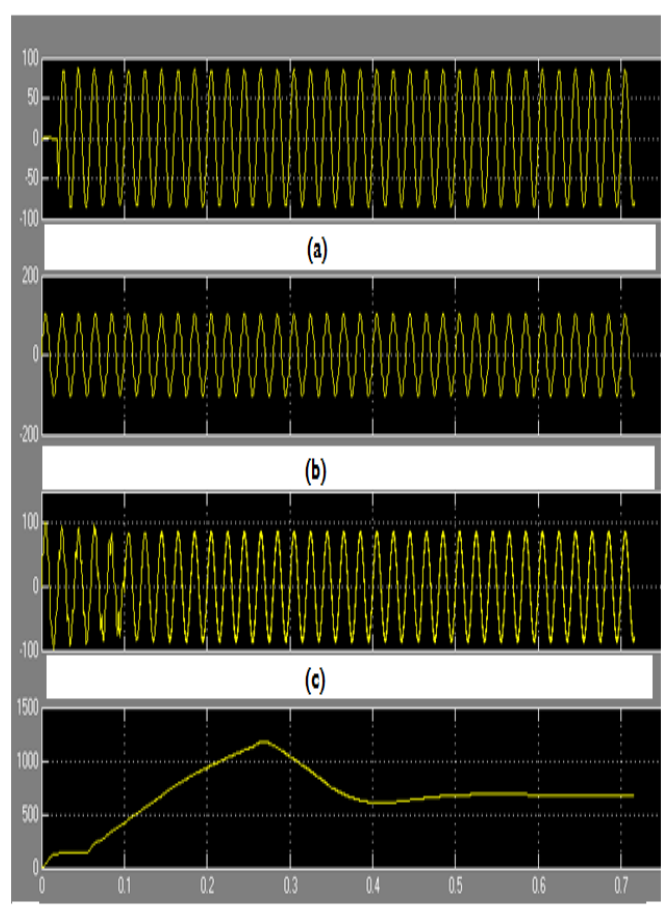

(d)

Figure 3. (a) Reference voltage, (b) Source voltage, (c) Load voltage, (d) DC link voltage for VSC based UPQC
Also it is seen in Figure 4, that the THD of load voltage is same as that of source voltage that is $11.18 \%$ before series filter is activated. This is shown in harmonic spectrum of source voltage in Figure.4(a). The Load voltage THD is reduced to just $1.40 \%$ by series filter as shown in Figure.4(b).

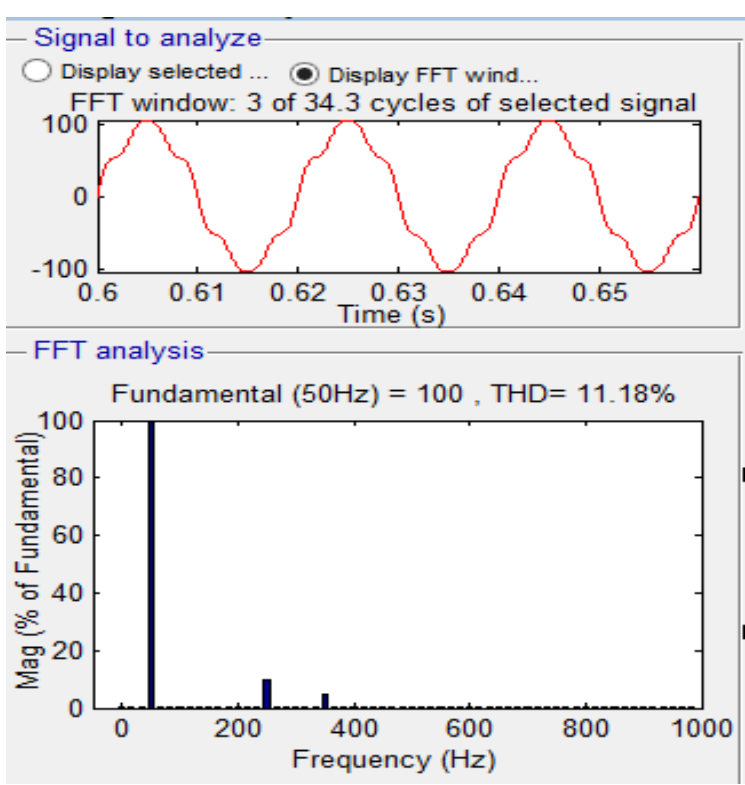

(a)

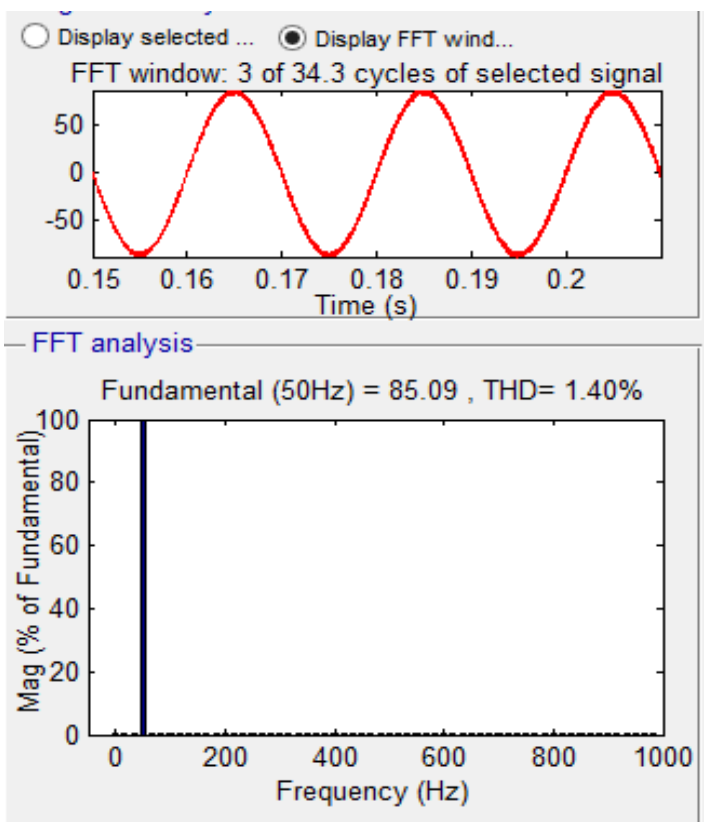

(b)

Figure 4. (a) THD of Source voltage, (b) THD of Load voltage for VSC based UPQC.

Now once the shunt active filter starts its operation at $\mathrm{t}=.05$, the source current becomes sinusoidal and the shunt filter starts compensation, it can be seen in Figure.5. Also it can be seen that load current is non-sinusoidal and has THD of $11.18 \%$, as shown in harmonic spectrum of Figure 6(b) but the source current is sinusoidal and has THD of $1.15 \%$ as shown in harmonic spectrum of source current in Figure 6(a). 


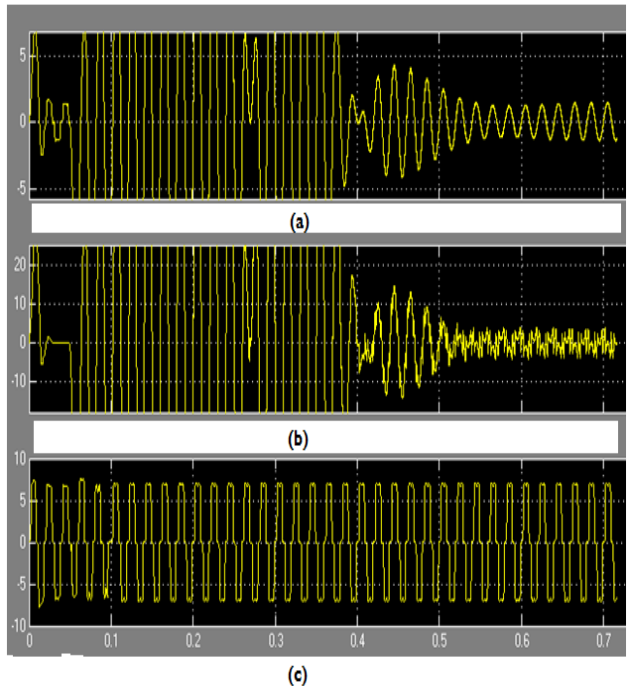

Figure5. (a) Source current, (b) Filter current and (c) Load current for VSC based UPQC.

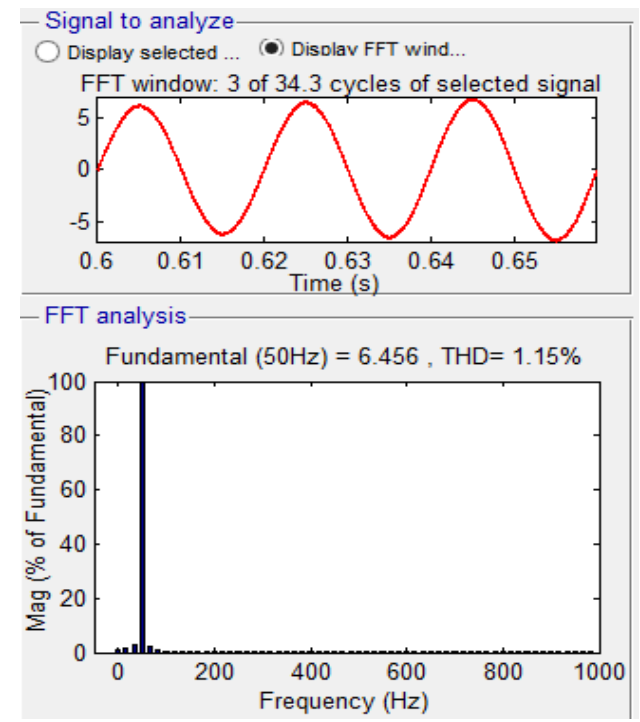

(a)

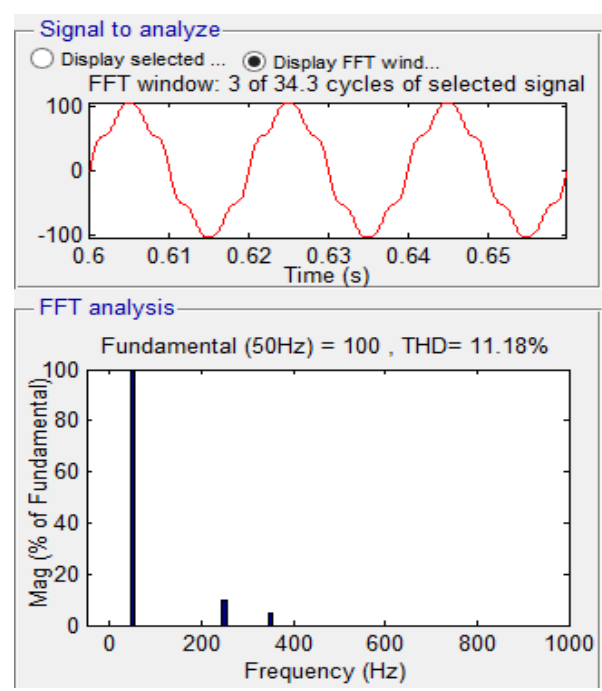

(b)

Figure 6. (a) THD of Source current, (b) THD of Load current for VSC based UPQC.

\subsection{Simulation Results using Fuzzy Logic Controlled VSC based UPQC}

To justify the performance capability, to overcome the slow response time of PI Controller, Fuzzy logic controlled VSC based UPQC is developed. A hysteresis band of $\pm 0.05 \mathrm{~A}$ is considered for simulation results. From Figure 7, it is shown that the Load voltage is same as source voltage, till the series filter is switched on at 0.1 second, as the series filter starts its compensation, the load voltage becomes purely sinusoidal and in phase with the reference voltage.

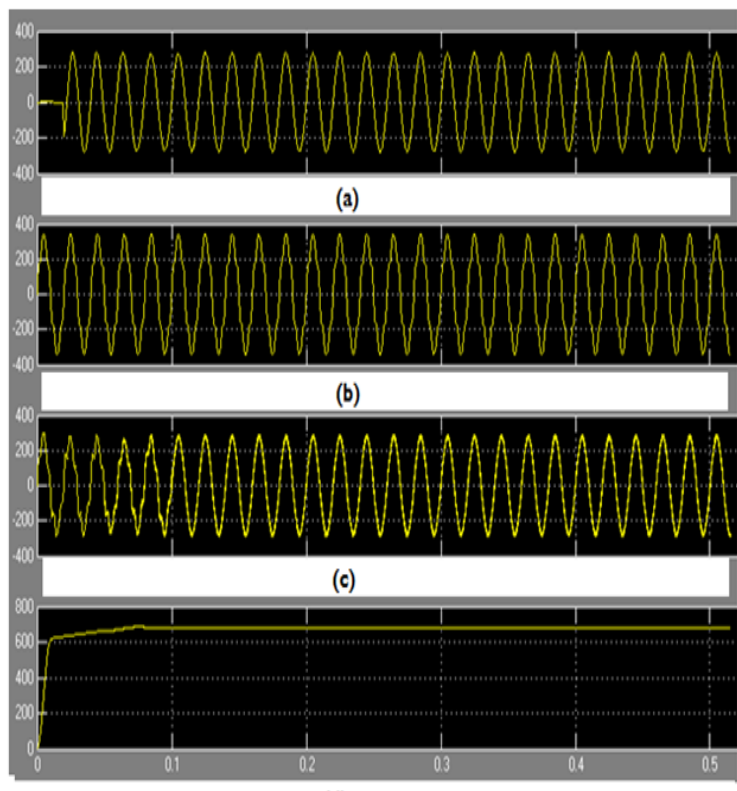

(d)

Figure 7. (a) Reference voltage, (b) Source voltage, (c) Load voltage, (d) DC link voltage, for Fuzzy logic controlled VSC based UPQC

The THD of load voltage is same as that of source voltage that is $10.32 \%$ before series filter is activated shown in harmonic spectrum of source voltage of Figure 8 (a). The load voltage THD is reduced to just $2.24 \%$ by series filter as shown in Figure 8(b) of harmonic spectrum for Load voltage.

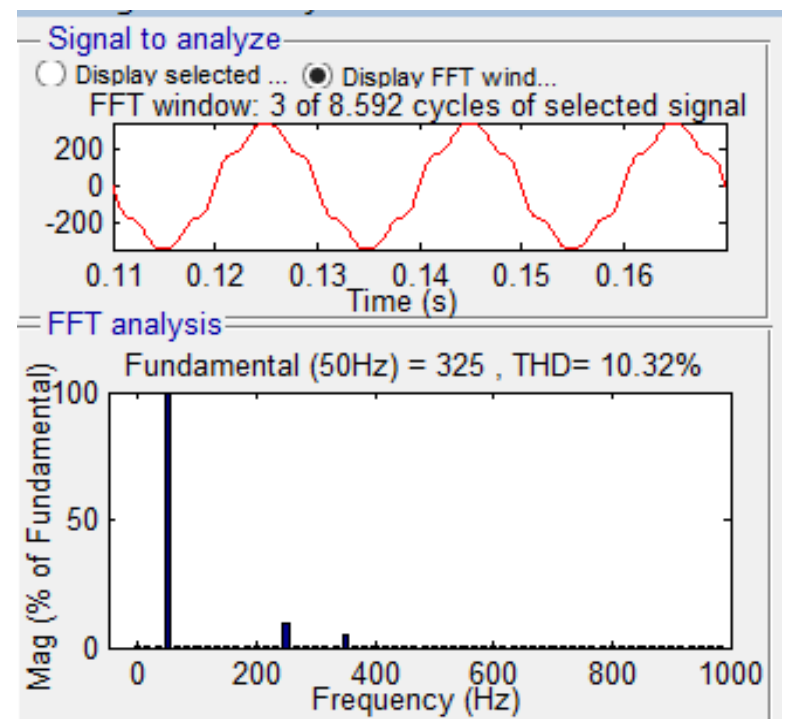

(a) 


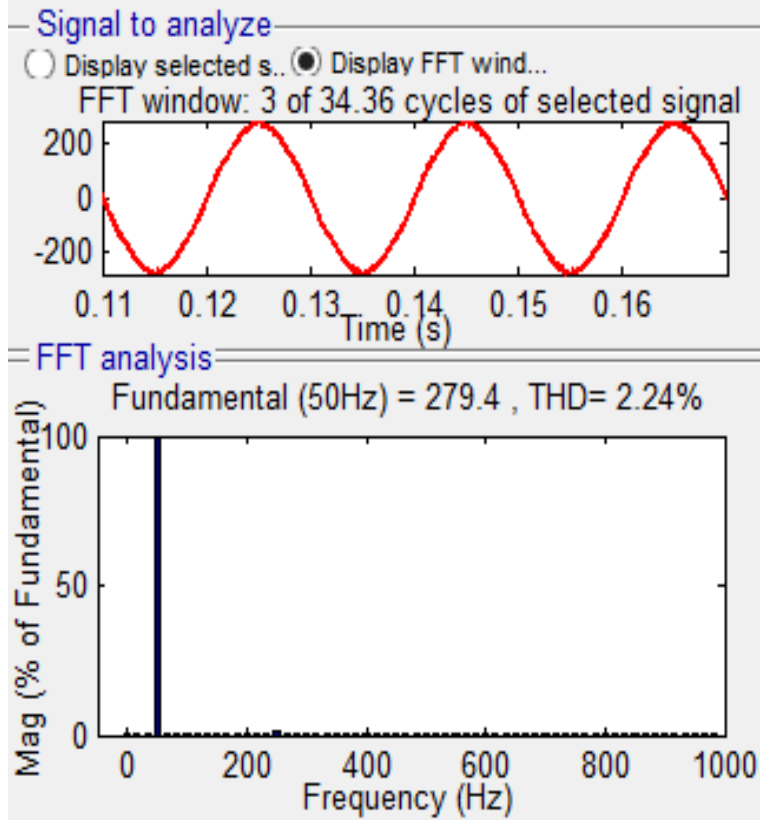

(b)

Figure 8. (a) THD of distorted Source Voltage, (b) THD of Load Voltage for Fuzzy logic controlled VSC based UPQC

The current outputs for fuzzy logic controlled VSC based UPQC are plotted in Figure 9, where the shunt active filter starts its operation on at $\mathrm{t}=0.05$ second, the source current becomes sinusoidal and the shunt filter starts compensation.

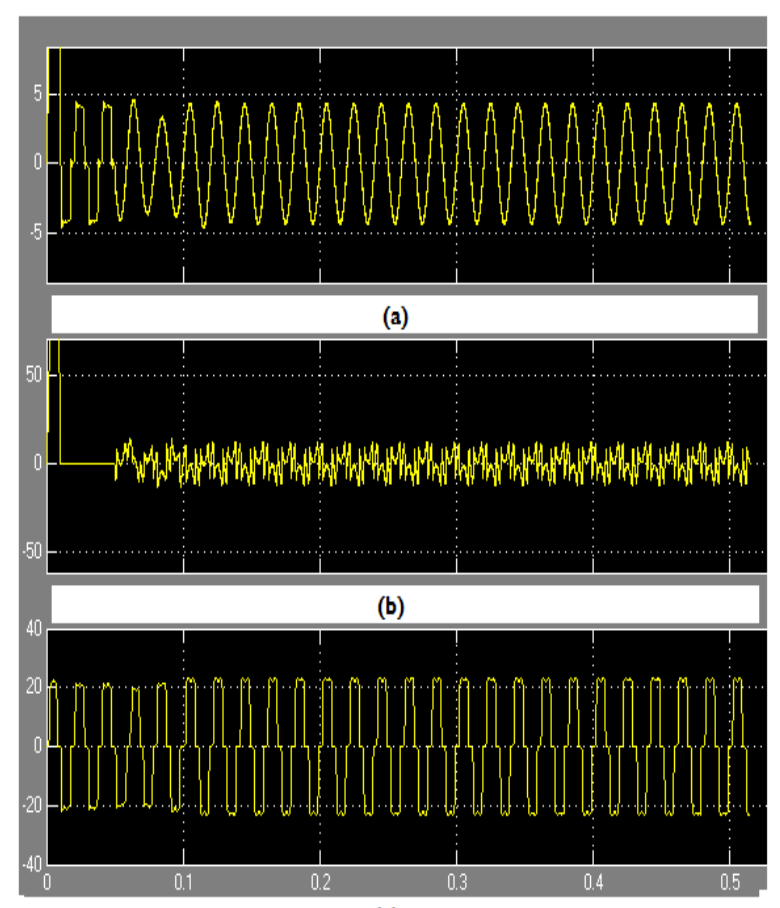

(c)

Figure 9. ( a ) Source current, (b ) Filter current and (c) Load current for Fuzzy logic controlled VSC based UPQC.

And it can be seen that the load current is non-sinusoidal and has THD of $10.32 \%$, as shown in harmonic spectrum of Figure 10(a) but the source current is sinusoidal when shunt filter starts its compensation and hence its THD is reduced to
$0.89 \%$ as shown in harmonic spectrum of source current in Figure 10(b).

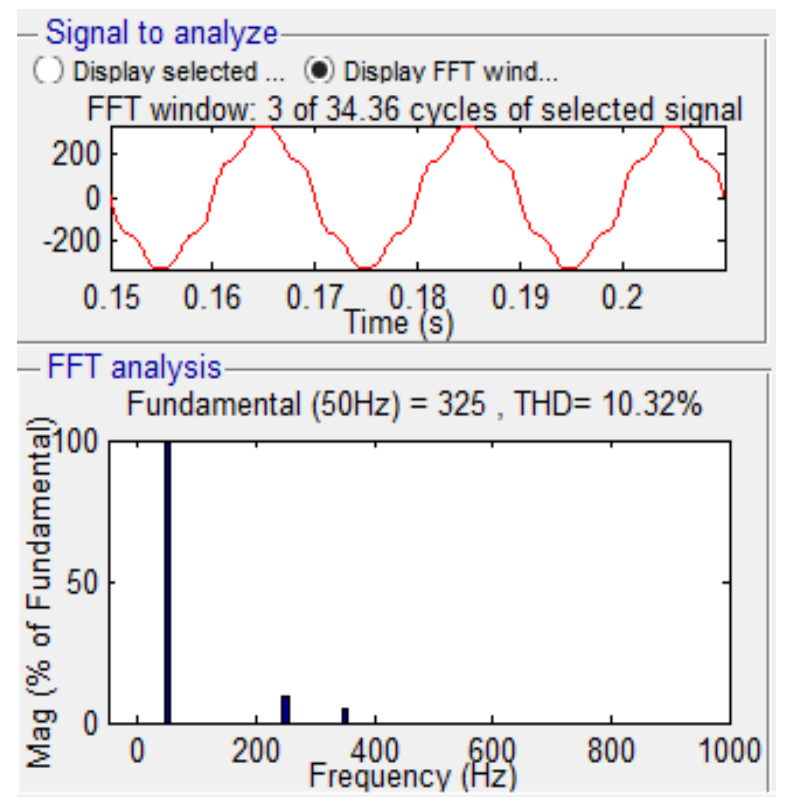

(a)

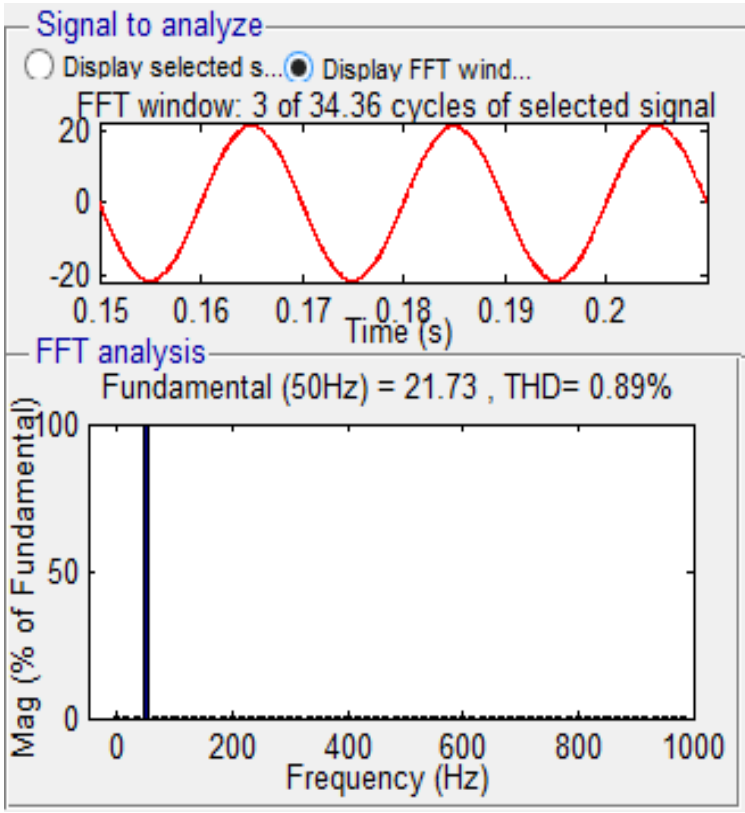

(b)

Figure 10. (a) THD of distorted Load Current (b) THD of Source Current for Fuzzy logic controlled VSC based UPQC.

Also it can be seen from both PI and Fuzzy logic controller used in VSC based UPQC that the comparison of both source voltage and source current are in phase and hence its unity power factor is maintained as shown in Figure 11. 


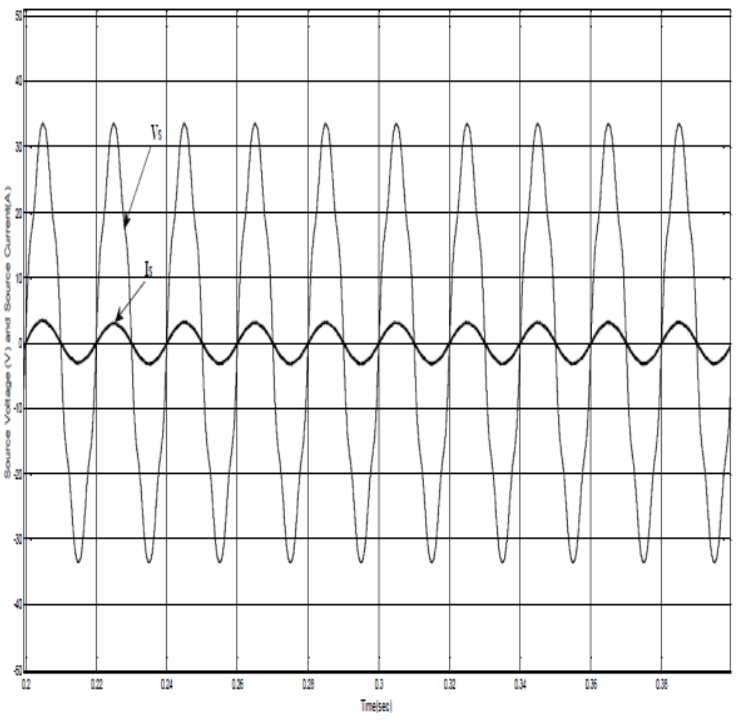

Figure 11. Plot of Source voltage (Vs) and Source current (Is) vs. time or PI and Fuzzy logic controlled VSC based UPQC

Upon comparing the outputs for PI and Fuzzy Controlled VSC based UPQC, we can see the response time of fuzzy logic controlled VSC based UPQC is less and DC voltage reaches its reference voltage earlier. There settling time for Fuzzy logic controller is 0.1 second whereas for PI controller it is 0.6 second. Thus Fuzzy Logic Controller acts quickly. The settling time is shown in Figure 12 and Figure 13.

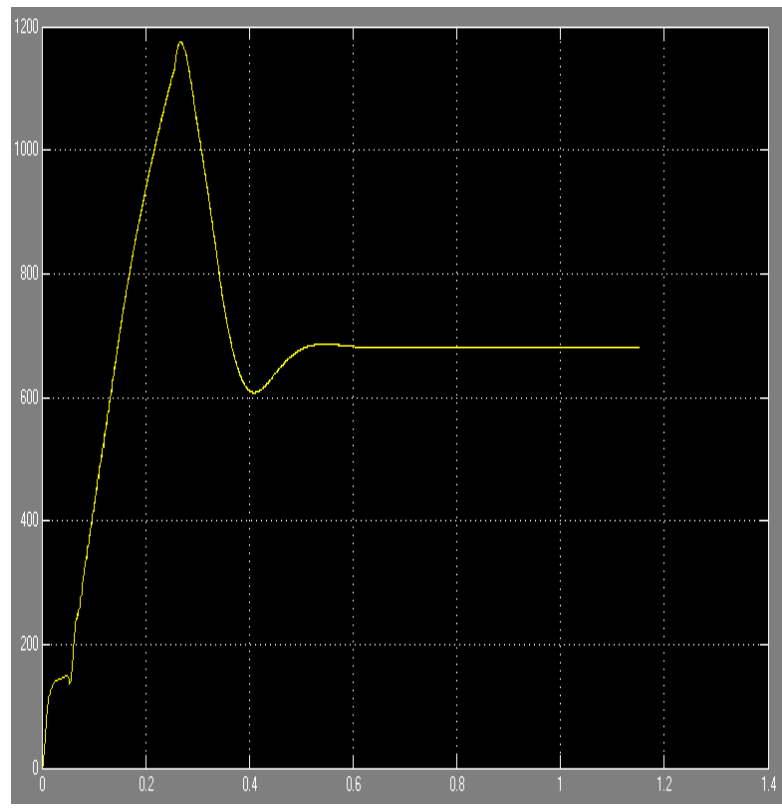

Figure 12. Response Time of DC link capacitor for PI controlled VSC based UPQC.

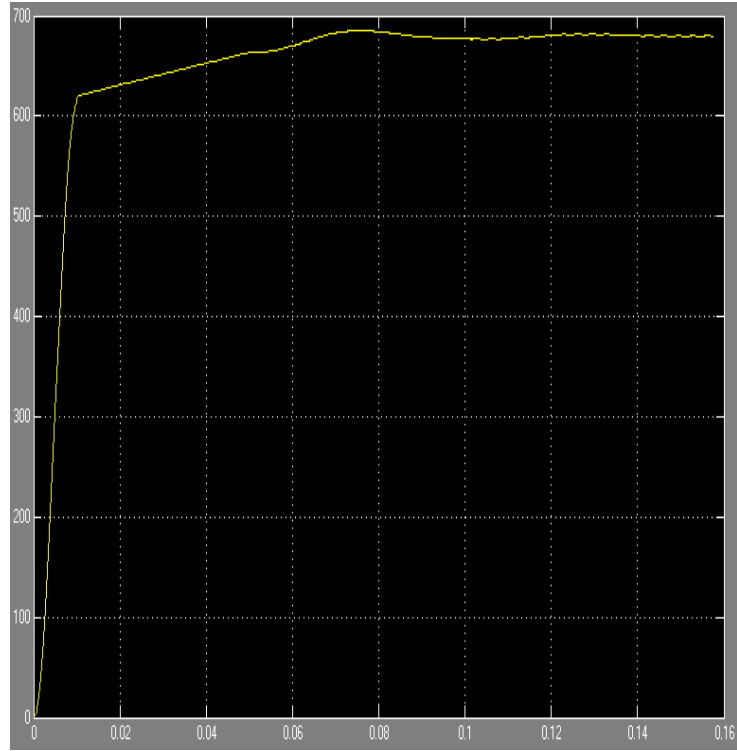

Figure 13. Response Time of DC link capacitor for Fuzzy logic controlled VSC based UPQC.

\section{COMPARISON OF PI AND FUZZY LOGIC CONTROLLED VSC BASED UPQC}

The proposed scheme provides compensation for both voltage and current harmonics. Also the power factor on source side is nearly unity and thus the PI controller as well as Fuzzy logic controller VSC based UPQC both can be used with high efficiency even when load power is low. As THD of load voltage (for $\mathrm{PI}=1.40 \%$, for Fuzzy $=2.24 \%$ ). Also source current has become sinusoidal (for PI=1.15\%, Fuzzy=0.89\%). Thus comparison is shown in the table below.

Table 2Comparative Analysis between Conventional PI Controller and Fuzzy Logic Controller

\begin{tabular}{|l|l|l|}
\hline $\begin{array}{l}\text { Performance } \\
\text { Parameters }\end{array}$ & $\begin{array}{l}\text { Conventional PI } \\
\text { Controller }\end{array}$ & $\begin{array}{l}\text { Fuzzy Logic } \\
\text { Controller }\end{array}$ \\
\hline Settling Time & $0.6 \mathrm{sec}$ & $0.1 \mathrm{sec}$ \\
\hline Overshoot & $1180 \mathrm{v}$ & $685.7 \mathrm{v}$ \\
\hline DC Voltage Ripple & $1 \mathrm{v}$ & $0.8 \mathrm{v}$ \\
\hline THD of Current & $1.15 \%$ & $0.89 \%$ \\
\hline
\end{tabular}

\section{CONCLUSION}

A comprehensive performance evaluation of Unified Power Quality Conditioner (UPQC) using PI and fuzzy logic controller for power quality improvement has been presented in this paper. The fuzzy logic based UPQC results in better performance with less THD of Source current, Lesser Settling time and near unity input power factor. Thus proposed fuzzy control technique is found extremely satisfactory to stabilize dc link voltage. UPQC provides compensation for voltage and current harmonics and are cost-effective, higher efficiency, enhanced reliability and better solutions for harmonic compensation with an extremely small-rated inverter in comparison to active power filter topologies and other options 
of power quality improvement. It can also be noticed from the results that the supply side current and load voltage harmonics levels are well below 5\%, the IEEE 519 standard.

\section{REFERENCES}

[1] IEEE standard 519-1992, IEEE recommended practices and requirement for harmonic control in electrical power systems, IEEE, Inc.1993.

[2] H. Akagi, "Performance and modeling of a shunt active filter for Installation on power distribution systems," to be presented at the 1996 IEEE-PES International Conference on Harmonics and Quality of Power, Oct. $16-18,1996$.

[3] Singh, G.K, Singh, A.K and Mitra, R. (2007)," A simple fuzzy logic based robust active power filter for Harmonics minimization under random load variation" Electric Power Systems Research 77.

[4] B. Han. B. Bae. S. Baek. and G. Jang. "New configuration of UPQC for medium-voltage application: IEEE Trans. Power Del. vo1. 21. pp. 1438- 1444. Ju1. 2006.

[5] Kesler. M .and E. Ozdemir. "Synchronous-ReferenceFrame-Based Control Method for UPQC Under Unbalanced and Distorted Load Conditions". IEEE Transactions on Industrial Electronics. 2011.

[6] Suja. K.R. and 1. Jacob Raglend. "Power quality improvement in grid connected wind Energy system using STATCOM". International Conference on Computing Electronics and Electrical Technologies (TCCEET). 2012.

[7] H. Fujita and H. Akagi. "The unified power quality conditioner: The integration of series- and shunt-active filters: IEEE Trans. Power Electron.vo1. 13. no. 2.pp.3 1 5-322.Mar. 1998.
[8] H. Akagi. "New trends in active filters for power conditioning: IEEE Trans. Ind. Appl.. vo1. 32. no. 6. pp. 1312-1322. Nov./Dec. 1996.

[9] J. Turunen, H. Tuusa, "Improvement of the voltage compensation performance of the series active power filter using a simple PI control method" IEEE Proceedings on Power Electronics and Applications, 2007 p.p 1-9.

[10] B. Singh, K. Al-Haddad, A. Chandra, "A Review of Active Power Filters for power quality Improvement", IEEE Trans on Industrial Electronics, Vol 45, No.5, Oct 1999, pp. 960-971.

[11] Khadkikar V. and Chandra A., "A new control philosophy for a unified power quality conditioner (UPQC) to coordinate load-reactive power demand between shunt and series inverters," IEEE Trans. Power Delivery. vol. 23, no. 4, pp. 2522-2534, 2008.

[12] A Ghosh and G. Ledwitch, "A unified power quality conditioner (UPQC) for simultaneous voltage and current compensation", Electric Power Systems Research, Vol. 59, 2001, pp. 55-63.

[13] Bhende, C.N., Mishra, S. and Jain S.K. (2006), “TSFuzzy-Controlled active power filter for load compensation", IEEE Transactions on Power Delivery, Vol. 21, No. 3, July. 2006.

[14] Sai Shankar, Ashwani Kumar, "Fuzzy based Unified Power Quality Conditioner" International conference on power, signals, controls and computation (EPSCICON),8-10 January 2014.

[15] K.R. Suja, I Jacob Raglend," Fuzzy based Unified Power Quality Conditioner" 2013 international conference on circuits, power, and computing technologies(ICCPCT2013) 